and writing of the paper. $\mathrm{AB}$ and AMdeLC are guarantors for the paper.

Funding: Research grant from Britain's Department for International Development.

Conflict of interest: None.

World Health Organisation. The Alma Ata declaration. Geneva: WHO, 1978.

2 World Bank. Investing in health. The world development report. Oxford: Oxford University Press, 1993.

3 Bhargava SK, Singh KK, Saxena BN, eds. A national collaborative study of identification of high risk families, mothers and outcome of their offsprings with particular reference to the problem of maternal nutrition, low birth weight, perinatal and infant morbidity and mortality in rural and urban slum communities. New Delhi: Indian Council of Medical Research, 1990.

4 Loevinsohn BP. Health education in developing countries: a methodological review of published articles. Int J Epidemiol 1990;19: 788-94.

5 Prasad B, Costello AM de L. Impact and sustainability of a "baby friendly" health education intervention at a district hospital in Bihar, India. BMJ 1995;310:621-3

6 Bolam A, Manandhar DS, Shrestha P, Manandhar B, Ellis M, Costello AM. Maternity care utilisation in the Kathmandu Valley: a community based study. J Nepal Med Assoc 1997;35:122-9.

7 Ashworth A, Waterlow JC. Infant mortality in developing countries. Arch Dis Child 1982;57:882-4

8 Human Development Report. Published for the United Nations Development Programme. Oxford: Oxford University Press, 1996.

9 World Bank. World development report 1990. Washington DC: World Bank, 1990

10 Parkin JM, Hey EN, Clowes JS. Rapid assessment of gestational age in the newborn infant. Arch Dis Child 1976;51:259.
11 Neupane S. A study on breast feeding status in rural and urban areas of central development region, Nepal. Kathmandu: Unicef, 1992.

12 Nepal multiple indicator surveillance: preliminary report. Kathmandu: National Planning Commission, His Majesty's Government of Nepal, 1995.

13 Malik Kundi MZ, Anjum M, Mull DS, Mull JD. Maternal perceptions of pneumonia and pneumonia signs in Pakistani children. Soc Sci Med 1993;37:649-60.

14 Tupasi TE, Miguel CA, Tallo VL, Bagasao TMP, Natividad JN, Valencia $\mathrm{LB}$, et al. Child care practices of mothers: implications for intervention in acute respiratory infections. Ann Tropical Paediatrics 1989;9:82-8.

15 United Nations Children's Fund. The state of the world's children 1993. Oxford: Oxford University Press, 1993.

16 Kafatos A, Tsitoura S, Pantelakis S, Doxiadis S. Maternal and infant health education in a rural Greek community. Hygie 1991;10:32-7.

17 American Public Health Association Work Group on Health Promotion/ Disease Prevention. Criteria for the development of health promotion and education programs. Am J Public Health 1987;77:89-92.

18 Hubley JH. Barriers to health education in developing countries. Health Educ Res 1986;1:233-45.

19 Oakley A, Fullerton D, Holland J, Arnold S, France-Dawson M, Kelley P, et al. Sexual health education interventions for young people: a methodological review BMJ 1995;310:158-62.

20 Gyorkos TW, Tannenbaum TN, Abrahamowicz M, Oxman AD, Scott EA, Millson ME, et al. An approach to the development of practice guidelines for community health interventions. Can J Public Health 1994;85:S8-13.

21 Maibach E, Murphy DA. Self-efficacy in health promotion research and practice: conceptualisation and measurement. Health Educ Res 1995; 10:37-50.

22 Bandura A. Self-efficacy: toward a unifying theory of behavioural change. Psychol Rev 1977;84:191-215.

(Accepted 6 February 1998)

\title{
Meta-analysis of short term low dose prednisolone versus placebo and non-steroidal anti-inflammatory drugs in rheumatoid arthritis
}

Peter C Gøtzsche, Helle Krogh Johansen

\begin{abstract}
Objective: To determine whether short term, oral low dose prednisolone ( $\leqslant 15 \mathrm{mg}$ daily) is superior to placebo and non-steroidal anti-inflammatory drugs in patients with rheumatoid arthritis.

Design: Meta-analysis of randomised trials of oral corticosteroids compared with placebo or a non-steroidal anti-inflammatory drug.

Setting: Trials conducted anywhere in the world.

Subjects: Patients with rheumatoid arthritis.

Main outcome measures: Joint tenderness, pain, and grip strength. Outcomes measured on different scales were combined by using the standardised effect size (difference in effect divided by SD of the measurements).

Results: Ten studies were included in the meta-analysis. Prednisolone had a marked effect over placebo on joint tenderness (standardised effect size $1.31 ; 95 \%$ confidence interval 0.78 to 1.83$)$, pain ( 1.75 ; 0.87 to 2.64$)$, and grip strength $(0.41 ; 0.13$ to 0.69$)$. Measured in the original units the differences were 12 (6 to 18) tender joints and $22 \mathrm{~mm} \mathrm{Hg} \mathrm{(5} \mathrm{mm} \mathrm{Hg} \mathrm{to}$ $40 \mathrm{~mm} \mathrm{Hg}$ ) for grip strength. Prednisolone also had a greater effect than non-steroidal anti-inflammatory drugs on joint tenderness $(0.63 ; 0.11$ to 1.16$)$ and pain (1.25; 0.26 to 2.24$)$, whereas the difference in grip strength was not significant $(0.31 ;-0.02$ to 0.64$)$. Measured in the original units the differences were 9
\end{abstract}

(5 to 12 ) tender joints and $12 \mathrm{~mm} \mathrm{Hg} \mathrm{(}-6 \mathrm{~mm} \mathrm{Hg}$ to $31 \mathrm{~mm} \mathrm{Hg}$ ). The risk of adverse effects during moderate and long term use seemed acceptable. Conclusion: Prednisolone in low doses $(\leqslant 15 \mathrm{mg}$ daily) may be used intermittently in patients with rheumatoid arthritis, particularly if the disease cannot be controlled by other means.

\section{Introduction}

Corticosteroids were first shown to be effective in patients with rheumatoid arthritis in 1949 in an uncontrolled study. ${ }^{1}$ In 1959, a two year randomised trial showed that an initial dose of prednisolone $20 \mathrm{mg}$ daily was significantly superior to aspirin $6 \mathrm{~g}$ daily. ${ }^{2}$ Important adverse effects were also noted, however, and the authors concluded that the highest acceptable dose for long term treatment was probably in the region of $10 \mathrm{mg}$ daily.

Corticosteroids have received renewed interest in recent years because of their possible beneficial effect on radiological progression. ${ }^{3}$ Tendencies towards such an effect were noted both in the early trials and in a recent report. ${ }^{4}$

These findings are interesting, but oral corticosteroids are still being used mainly for their symptomatic effect-for example, for acute exacerbations of rheumatoid arthritis and as "bridge therapy" before slow acting drugs have taken effect. ${ }^{5}$ The effect of low doses
Editorial by

Dennison and Cooper

Nordic Cochrane

Centre,

Rigshospitalet, Department 7112

Tagensvej $18 \mathrm{~B}$,

DK-2200

Copenhagen $\mathrm{N}$

Denmark

Peter C Gøtzsche, director

Helle Krogh

Johansen,

senior researcher

Correspondence to: Dr Gøtzsche p.c.gotzsche@ cochrane.dk

BMJ 1998;316:811-8 
has been variable, however, and was questioned as late as 1995 when the most recent trial of low dose steroids was published. ${ }^{6}$ We therefore performed a systematic review of randomised trials that compared corticosteroids, given at a dose equivalent to no more than $15 \mathrm{mg}$ prednisolone daily, with placebo or with non-steroidal anti-inflammatory drugs. Our review is limited to the short term effect-that is, as recorded within the first weeks of treatment. In an analysis of the adverse effects of steroids, however, we also included long term trials and matched cohort studies.

\section{Methods}

All randomised studies that compared an oral corticosteroid with placebo or a non-steroidal antiinflammatory drug in patients with rheumatoid arthritis were eligible if they reported clinical outcomes within 1 month after the start of treatment. When there were data from several visits, the data that came closest to 1 week of treatment were used for the analyses. We excluded studies with high dose steroids (exceeding an equivalent of $15 \mathrm{mg}$ prednisolone daily); studies of combination treatments-for instance, of a steroid and a non-steroidal anti-inflammatory drug; and studies that used quasi-randomisation methods, such as allocation by date of admission or by toss of a coin (no such studies were actually found). The outcome variables were joint tenderness (usually Ritchie's joint index), pain, and grip strength.

Medline was searched from 1966 onwards and most recently updated in September 1997. We used the Explode option (which searches for a broad term plus related narrower items) for "glucocorticoids" or "glucocorticoids, -synthetic" (for all subheadings) combined with Explode "arthritis-rheumatoid" (for all subheadings) and with "placebos" or "comparative study" in $\mathrm{MeSH}$. The reference lists were scanned for additional trials, and an archive in possession of one of the authors was searched. As most of the retrieved trials were very old and the steroid drugs were nonproprietary ones authors and companies were not asked about possible unpublished studies. We did not handsearch journals for relevant trials as this work is

Table 1 General characteristics of studies included in meta-analysis of low dose prednisolone in treatment of rheumatoid arthritis

\begin{tabular}{|c|c|c|c|c|}
\hline \multirow[b]{2}{*}{ Study } & \multirow[b]{2}{*}{ Design } & \multicolumn{2}{|c|}{ Study drugs } & \multirow{2}{*}{$\begin{array}{l}\text { Length of } \\
\text { treatment } \\
\text { (days) }\end{array}$} \\
\hline & & Prednisolone & Control & \\
\hline Berry $1974^{33}$ & Crossover & $15 \mathrm{mg}$ & Placebo & 7 \\
\hline Boardman $1967^{34 \star}$ & Crossover & $7.5 \mathrm{mg}$ & Placebo & 7 \\
\hline Böhm $1967^{35} 36$ & Crossover & $2.5 \mathrm{mg}$ & Placebo & 8 \\
\hline Dick $1970^{37}$ & Crossover & $10 \mathrm{mg}$ & $\begin{array}{l}\text { Placebo; ibuprofen } 1200 \mathrm{mg} \text {; } \\
\text { aspirin } 4 \mathrm{g \dagger}\end{array}$ & 7 \\
\hline Gestel $1995^{632}$ & Parallel & $10 \mathrm{mg}$ & Placebo & $7 \ddagger$ \\
\hline Jasani $1968^{38}$ & Crossover & $15 \mathrm{mg}$ & $\begin{array}{l}\text { Placebo; ibuprofen } 750 \mathrm{mg} \text {; } \\
\text { aspirin } 5 \mathrm{g \dagger}\end{array}$ & 7 \\
\hline Lee $1973^{39}$ & Crossover & $15 \mathrm{mg}$ & Placebo; aspirin $5 \mathrm{~g}$ & 7 \\
\hline Lee $1973^{4041}$ & Parallel & $15 \mathrm{mg}$ & Placebo; aspirin $3.9 \mathrm{~g}$ & 14 \\
\hline Lee $1974^{42}$ & Crossover & $10 \mathrm{mg}$ & Placebo; sodium salicylate $4 \mathrm{~g}$ & 7 \\
\hline Stenberg $1992^{43}$ & Crossover & $3 \mathrm{mg}$ & Placebo & $5 \S$ \\
\hline
\end{tabular}

*We included two patients in analysis (excluded by authors because of too little difference in joint size) by assuming that difference in grip strength was 0 .

†Average of ibuprofen and aspirin used in analysis.

$\ddagger$ One week data provided by authors.

§Each flare treated for 5 days; three randomised patients who were excluded because of poor response to prednisolone in introductory test period included in analysis by assuming that difference between prednisolone and placebo was 0 . already being organised by the Cochrane Collaboration for all medical journals, including specialist rheumatological journals. The results of these handsearches are made available in the Cochrane Controlled Trials Register in The Cochrane Library, ${ }^{7}$ which we searched with prednisolone and prednisone as text words combined with rheumatoid.

Decisions on which trials to include were taken independently by two observers based only on the methods sections of the trials; disagreements were resolved by discussion. Details on the nature and dose of treatments, number of randomised patients, the randomisation and blinding procedures, and exclusions after randomisation were noted. When an outcome was measured on the same scale in all trials we calculated the weighted mean difference as the summary estimate for the effect. As the outcomes were often measured on different scales, however, even when they referred to the same quality-for example, tender joints-we also calculated standardised effect measures. ${ }^{8}$ With this method the difference in effect between two treatments is divided by the standard deviation of the measurements. By that transformation the effect measures become dimensionless, and outcomes from trials which have used different scales may therefore often be combined. As an example, the tender joint count may be recorded either as the number of tender joints or as Ritchie's index, in which each joint is scored on a scale from 0 to 3 for pain on firm palpation and the scores added. Often the two types of counts will give similar values, but if the patients have very severe disease Ritchie's index may be higher. The standard deviation will then also be higher, however, and by dividing the counts with their standard deviations (for example, of the baseline measurements) the effect sizes will be of the same magnitude.

The random effects model ${ }^{9}$ was used if $\mathrm{P}<0.10$ for the test of heterogeneity; otherwise a fixed effects analysis was performed. As data from crossover trials were reported in only summary form, as if they had been generated from a group comparative trial, we analysed them accordingly. We therefore assumed that no important carryover effects had occurred.

\section{Results}

Twenty eight randomised trials were initially identified, several of which had been published more than once. Eighteen trials were excluded for various reasons. ${ }^{24510-31}$ Nine trials did not fulfil the inclusion criteria for the meta-analysis: five had studied combinations of drugs ${ }^{1017-192731}$; two used too high a dose ${ }^{20-23}$; in one, $4 \mathrm{mg}$ methylprednisolone was given to all the patients in the placebo group ${ }^{28}$; and one concerned patients with juvenile rheumatoid arthritis (this trial found prednisolone to be significantly better than placebo).$^{24}$

The other nine excluded studies were potentially eligible for the meta-analysis. However, one was a five way crossover trial with a grossly unbalanced designfor instance, placebo was given to $9,13,3,6$, and 6 patients during weeks $1,2,3,4$, and 5 , respectively. ${ }^{12}$ Because of regression towards the mean we found it inappropriate to include this trial. Another trial was also unbalanced as the steroid group was kept mobile 


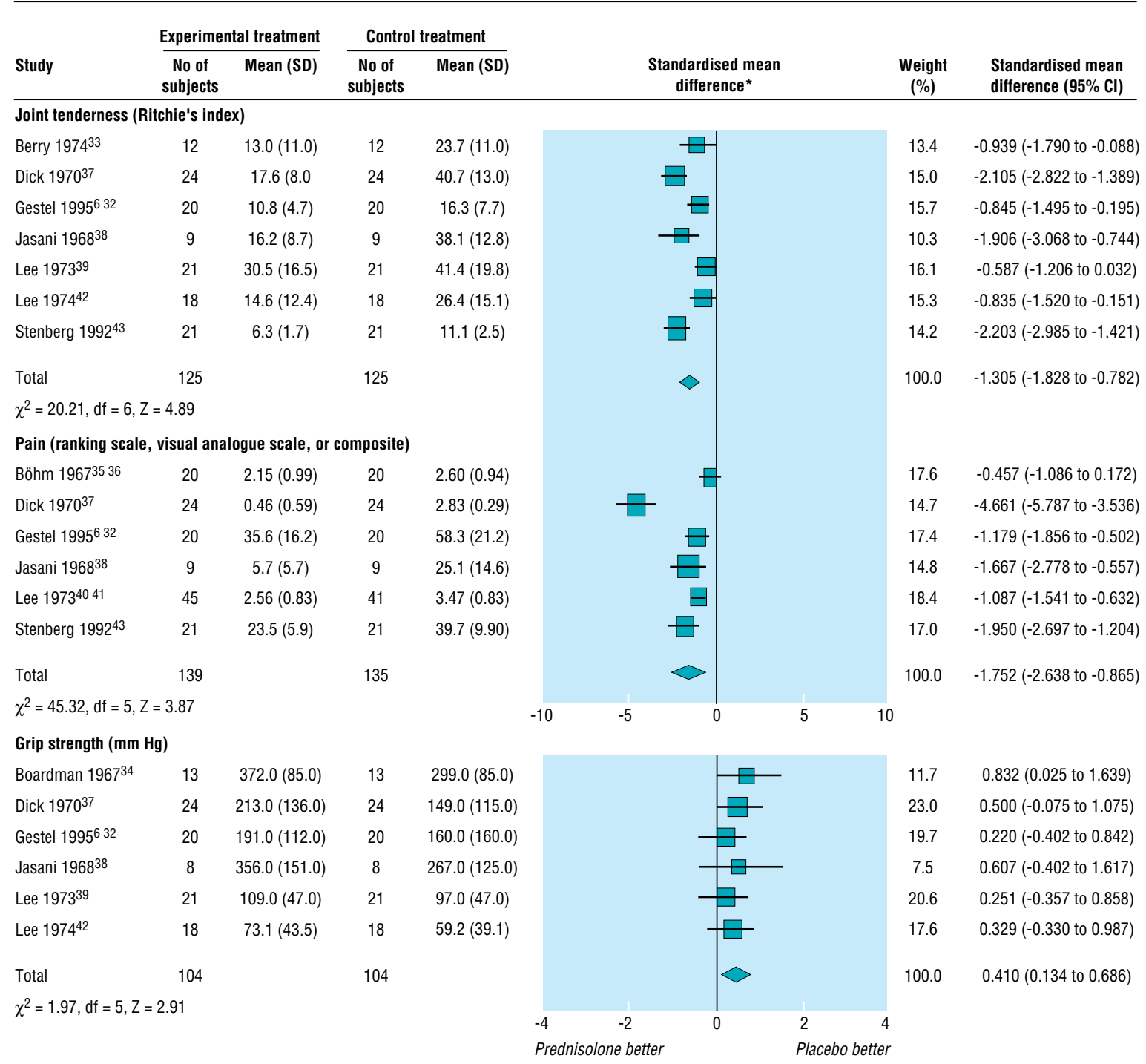

Fig 1 Results of meta-analysis of low dose prednisolone versus placebo for control of rheumatoid arthritis, according to joint tenderness, pain, and grip strength. *If prednisolone is better than control standardised mean difference is negative for joint tenderness and pain but positive for grip strength. Random effects model was used for joint tenderness and pain, and fixed effects model for grip strength

whereas the control group received bed rest and splints for the inflamed joints. ${ }^{25}$ Two trials were too poorly reported to be usable for the metaanalysis, ${ }^{15}{ }^{1626}$ and one reported only on joint size. ${ }^{29}$ Three of these four trials found prednisolone or prednisone to be significantly more effective than placebo; the fourth compared prednisolone and indomethacin and gave no numerical data but just reported that there was "no significant difference in response."26 The four other excluded trials were long term studies that did not report short term data. ${ }^{411}{ }^{13}$ We contacted the authors of these studies to make sure that no short term data had been recorded without being reported. This was confirmed in two cases ${ }^{411}$; we were unable to contact any of the authors of the other two studies or of the study that reported only joint size ${ }^{29}$ to ensure that no further variables had been recorded.

Ten studies were included in the meta-analysis (table 1). ${ }^{62-43}$ Most of the studies were quite old and rather small. In all but one ${ }^{35}{ }^{36}$ the criteria of the American Rheumatism Association for classical or definite rheumatoid arthritis were fulfilled. Age, proportion of women, and duration of disease were reported in only half of the studies but they were typical for studies in rheumatoid arthritis: mean age was 55 years, two thirds were women, and the mean (range) duration of disease was 6 (2.1 to 9.6) years. As expected for patients enrolled in steroid trials the severity of the disease, expressed as number of tender joints or Ritchie's tender joint index, was quite pronounced (see fig 1). Prednisolone was used in six trials and prednisone in four. ${ }^{62} 34404143$ As prednisone is equipotent with prednisolone and is a pro-drug of prednisolone we have used "prednisolone" as a general term throughout the paper. The doses were $2.5,3.0$, and $7.5 \mathrm{mg}$ in one study each, $10 \mathrm{mg}$ in three studies, and $15 \mathrm{mg}$ in four. The median length of treatment was 1 week.

The randomisation method was not described in any of the trial reports but details were obtained from the authors for one of the studies in which the treatment allocation seemed to have been adequately concealed. ${ }^{62}$ These authors also provided short term data from their long term trial. All studies were double blind apart from a single blind study in which the patients seemed to have been blinded. ${ }^{40}{ }^{41}$ Eight of the studies were of a crossover design but only one of them reported having tested for sequence effects. ${ }^{43}$ Apart from one study $y^{43}$ the tender joint count was recorded as 


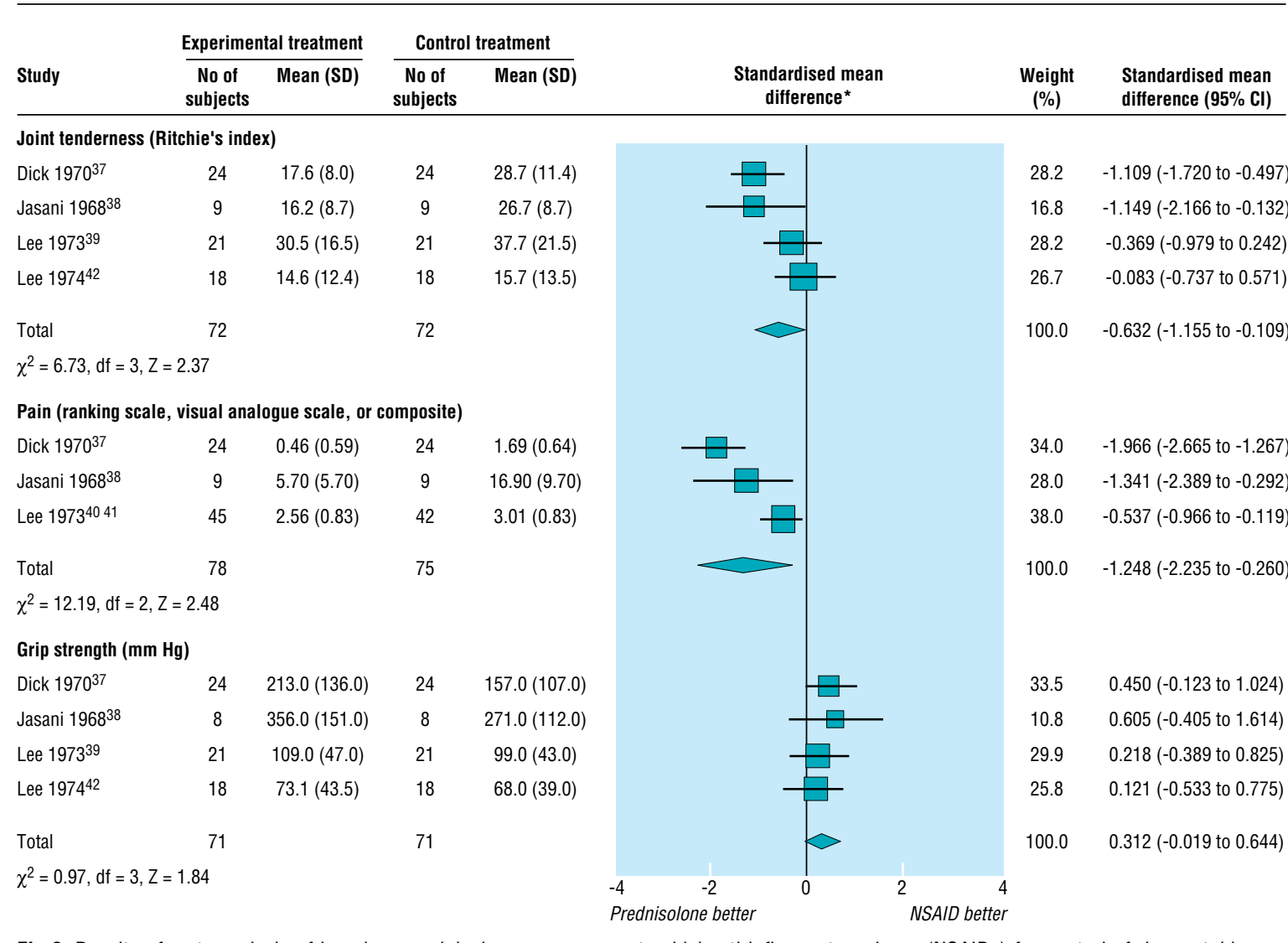

Fig 2 Results of meta-analysis of low dose prednisolone versus non-steroidal anti-inflammatory drugs (NSAIDs) for control of rheumatoid arthritis, according to joint tenderness, pain, and grip strength. *If prednisolone is better than control standardised mean difference is negative for joint tenderness and pain but positive for grip strength. Random effects model was used for joint tenderness and pain, and fixed effects model for grip strength

Ritchie's index; pain was recorded on a ranking scale with 4 or 5 classes in two studies, ${ }^{35} 364041$ on a visual analogue scale in two studies, ${ }^{6233}$ and as a composite pain index in two studies. ${ }^{38} 43$

The results of the meta-analysis are shown in figures 1 and 2. It should be noted that if prednisolone is better than control, the standardised effect size is negative for joint tenderness and pain but positive for grip strength.

Prednisolone had a clear effect over placebo on joint tenderness (standardised effect size $-1.31 ; 95 \%$ confidence interval -1.83 to -0.78$)$, pain $(-1.75 ;-2.64$ to -0.87 ), and grip strength $(0.41 ; 0.13$ to 0.69$)$. Measured in the original units, in an analysis of the weighted mean difference the difference between prednisolone and placebo was 12 tender joints (95\% confidence interval 6 to 18 ; test for heterogeneity $\chi^{2} 46.42, \mathrm{df}=6 ; \mathrm{P}<0.00001$ ). The effect on grip was always measured in $\mathrm{mm} \mathrm{Hg}$ or in $\mathrm{kPa}$. After conversion of $\mathrm{kPa}$ to $\mathrm{mm} \mathrm{Hg}$ the superiority of prednisolone over placebo was $22 \mathrm{~mm} \mathrm{Hg}(95 \%$ confidence interval $5 \mathrm{~mm} \mathrm{Hg}$ to $40 \mathrm{~mm} \mathrm{Hg}$; test for heterogeneity $\chi^{2} 5.47, \mathrm{df}=5 ; \mathrm{P}=0.36$ ).

Prednisolone also had a greater effect than non-steroidal anti-inflammatory drugs on joint tenderness $(-0.63 ;-1.16$ to -0.11$)$, pain $(-1.25 ;-2.24$ to $-0.26)$, and grip strength, although the difference in grip strength was not significant $(0.31 ;-0.02$ to 0.64$)$. Measured in the original units the difference between prednisolone and non-steroidal anti-inflammatory drugs was 9 tender joints ( 5 to 12 ; test for heterogeneity $\chi^{2} 4.06, \mathrm{df}=3 ; \mathrm{P}=0.26$ ). The effect on grip strength showed a non-significant superiority of prednisolone over non-steroidal anti-inflammatory drugs of $12 \mathrm{~mm} \mathrm{Hg}$ ( $-6 \mathrm{~mm} \mathrm{Hg}$ to $31 \mathrm{~mm} \mathrm{Hg}$; test for heterogeneity $\left.\chi^{2} 3.03, \mathrm{df}=3 ; \mathrm{P}=0.39\right)$.

\section{Discussion}

Our meta-analysis has shown that low dose prednisolone is not only highly effective but also significantly more effective than non-steroidal anti-inflammatory drugs. The point estimate for the difference in effect between prednisolone and non-steroidal antiinflammatory drugs on grip strength was $12 \mathrm{~mm} \mathrm{Hg}$. It is interesting that the point estimate for the difference in effect between non-steroidal anti-inflammatory drugs and placebo was also found to be $12 \mathrm{~mm} \mathrm{Hg}$ in an earlier meta-analysis. ${ }^{44}$ It was not surprising that the difference in effect on grip strength between prednisolone and non-steroidal anti-inflammatory drugs was not significant as this effect measure is considerably less sensitive to change than pain and joint tenderness. ${ }^{45}$

We used a random effects model for some of the analyses because of heterogeneity. Which model to use is a matter of dispute among statisticians, but the results were not too different if analysed with a fixed effects model, which gave standardised effect sizes for prednisolone versus placebo of $-1.23(-1.51$ to -0.95$)$ for joint tenderness and -1.35 ( -1.63 to -1.08$)$ for pain, and for prednisolone versus non-steroidal anti-inflammatory drugs of $-0.61(-0.95$ to -0.27$)$ for joint tenderness and $-0.97(-1.32$ to -0.63$)$ for pain. 


\section{Heterogeneity}

It is always important to try to explain heterogeneity. Our attempts to do so, however, have been rather unsuccessful. As most of the studies were done more than 20 years ago an obvious reason for the heterogeneity could be that the earlier trials had overestimated the effect-for instance, because of insufficiently concealed randomisation methods. ${ }^{46}$ The methodological quality of the trials was acceptable in the whole time span of nearly 30 years, however, and it was, for example, similar to the quality of comparative non-steroidal anti-inflammatory drug trials. ${ }^{47}$ In accordance with this there were no time trends for the differences in joint tenderness and pain between prednisolone and placebo. There was marginal heterogeneity $(\mathrm{P}=0.08)$ for the difference between prednisolone and non-steroidal anti-inflammatory drugs in joint tenderness, but the heterogeneity disappeared when the analysis was performed in the original units $(\mathrm{P}=0.26)$.

Blinding did not seem to have been important for heterogeneity. Only one trial was not double blind, and this trial did not yield larger effect estimates than the other trials. Small trials may exaggerate the effect because of publication bias. ${ }^{48}$ This possibility could not be studied as the trials were all rather small and contributed similar weights to the meta-analysis. The effect was so pronounced, however, that it would have been unreasonable to plan large trials; in this respect steroid trials resemble trials of non-steroidal antiinflammatory drugs that have also shown convincingly their superiority over placebo in small crossover trials. ${ }^{45}$ One would need to postulate that an unrealistically large number of unpublished trials existed that had shown no effect before the positive effect shown in our meta-analysis would become nullified.

An obvious cause for the heterogeneity could be varying degrees of concomitant treatment with additional non-steroidal anti-inflammatory drugs. Although sometimes stated in trial protocols, it may be difficult to ensure in practice that patients do not take additional drugs. As there was very sparse information on drug intake in the reports this possibility could not be evaluated. Another source could be the use of different measurement scales. Pain, for example, was measured on three different types of scale. They were all ranking scales, and we would therefore definitely have preferred to analyse pain with rank sum tests or as binary data after reduction of the level of measurement. The problem in analysing rank data with parametric methods is not only that they are often far from being normally distributed but also that we do not know the "distances" between the levels on the scale. As the original authors had used parametric statistics we decided to do so as well because our only other option was to discard the data.

Surprisingly, there was no clear relation between dose and effect despite the fact that the doses varied from $2.5 \mathrm{mg}$ to $15 \mathrm{mg}$ daily. It was not the aim of our review, however, to study dose-response relations, which are elucidated more reliably in studies where patients are randomised to different doses. A remarkable effect was seen in a study in which the average dose was only $3 \mathrm{mg}$ daily but where the patients were allowed to start on $7.5 \mathrm{mg}$ when they experienced flares of the arthritis and were advised to take nothing when they were well. ${ }^{43}$ This study suggests that it could be an advantage to take steroids intermittently, which would also diminish their adverse effects.

We could be criticised for including crossover trials for which we assumed but could not test that no important carryover effects had occurred. Our arguments for doing this were threefold. Firstly, it is not uncommon in statistical analyses to make necessary assumptions which cannot be properly tested in the data at hand-for example, in multiple regression analyses. Secondly, the problem with crossover trials is not only of a statistical nature, it also has an important ethical dimension. As crossover trials almost without exception are poorly reported and do not allow checks of the assumptions for this design, ${ }^{47}$ we would have to discard a vast amount of useful information in the literature in practically all areas of health care if we chose to behave as statistical purists. This would lead to much superfluous research being done, which is not in the best interest of patients or society. Thirdly, and most importantly, one would not expect carryover problems for drugs with relatively quick and reversible symptomatic effects such as steroids or non-steroidal anti-inflammatory drugs in patients with rheumatoid arthritis. In fact in a meta-analysis of non-steroidal anti-inflammatory drugs very similar results were obtained with the two trial designs. ${ }^{44}$ For these reasons we believe our approach is justified. Only two studies were of a group comparative design, and the heterogeneity we found could not be explained by type of design.

\section{Included trials}

The titles of the included trials were generally quite uninformative and some of the them were not easy to find as they were performed within experiments designed to study other factors. Several of the studies were retrieved from an archive in possession of one of the authors assembled during work on a thesis ${ }^{50}$ before the electronic data searches were performed. The authors of the most recent study in this topic ${ }^{62}$ had found only one of five trials comparing steroids with placebo in long term studies and none of the nine short term trials included in our review. These short term trials were described in 11 reports that were all indexed in Medline with the term for rheumatoid arthritis; in addition, all but one ${ }^{38}$ contained the terms for clinical trial or comparative study. Further, all nine trials were identifiable by using the search term "placebo*" and ("prednisone" or "prednisolone"). This illustrates the value of a systematic and careful search of the literature before starting new clinical trials, and funding bodies and ethical review committees should demand a systematic review of the relevant literature before approving of new clinical research. ${ }^{51}$

Recently, another meta-analysis of low dose corticosteroids ( $\leqslant 15 \mathrm{mg}$ prednisolone daily) in rheumatoid arthritis was published. ${ }^{52}$ This meta-analysis looked at moderate term effectiveness and focused on the outcome after 6 months; only two of the included trials were the same as in our meta-analysis. ${ }^{62}{ }^{32}$ These authors also noted heterogeneity, but they did not explore possible reasons for it or show the individual results for each trial; they only showed the combined result for each outcome. The weighted mean difference between steroid and placebo was surprisingly small, corresponding to only 2.4 tender joints (four trials, 
Table 2 Details of eight trials and two matched cohort studies used in meta-analysis of low dose prednisolone in treatment of rheumatoid arthritis

\begin{tabular}{|c|c|c|c|c|}
\hline Study & $\begin{array}{l}\text { Equivalent dose of } \\
\text { prednisolone }\end{array}$ & $\begin{array}{l}\text { Length of } \\
\text { treatment }\end{array}$ & $\begin{array}{l}\text { No of patients taking } \\
\text { steroids/ control }\end{array}$ & Reported major adverse effects (defined by authors) \\
\hline \multicolumn{5}{|l|}{ Randomised trials v placebo } \\
\hline Chamberlain $1976^{11}$ & 3 or $5 \mathrm{mg}$ & 2 years & $30 / 19$ & Vertebral fracture in $1 v 1$; no proved peptic ulcers \\
\hline Harris $1983^{5}$ & $5 \mathrm{mg}$ & 6 months & $18 / 16$ & $\begin{array}{l}\text { Two fractures on steroid, no ocular changes; all patients subjected to lumbar spine } \\
\text { films and ophthalmic examination }\end{array}$ \\
\hline Stenberg $1992^{43}$ & $3 \mathrm{mg}$ & 3 months & $22 / 22$ & None (only mild adverse effects, similar to placebo group) \\
\hline Gestel $1995^{6} 32$ & $10 \mathrm{mg}$ & 3 months & $20 / 20$ & No fractures; all patients had lateral spine radiographs taken \\
\hline Kirwan $1995^{4}$ & $7.5 \mathrm{mg}$ & 2 years & $61 / 67$ & $\begin{array}{l}\text { None (two cases of hypertension/weight gain on steroid, two with diabetes and } \\
\text { hypertension, respectively, on placebo) }\end{array}$ \\
\hline \multicolumn{5}{|l|}{ Randomised trials $v$ aspirin } \\
\hline Empire Rheumatism Council $1955^{13}$ & $15 \mathrm{mg}$ & 1 year $^{*}$ & $50 / 50$ & Hypertension in $2 v 0$ and indigestion in $1 v 5$ caused drop out \\
\hline Joint Committee $1954^{2021}$ & $16 \mathrm{mg} \dagger$ & 2 years* & $30 / 32$ & $\begin{array}{l}\text { None (moon face or rubicundity in } 11 \text {, depression in } 5 \text {, euphoria in } 4 v \text { tinnitus in } 11 \text {, } \\
\text { deafness in } 10 \text {, nausea, dyspepsia or anorexia in } 13 \text { reported in first year. Similar } \\
\text { adverse effects in second year (one drop out on each drug, no fractures or cataract)) }\end{array}$ \\
\hline Joint Committee $1959^{2}$ & $10 \mathrm{mg} \ddagger$ & 2 years $^{*}$ & $45 / 39$ & $\begin{array}{c}\text { Fractures in } 2 v 1 \text {, psychosis in } 2 v 0 \text {, ulcers in } 3 v 0 \text {, infections in } 4 v 3 \text {. All had spinal } \\
x \text { rays. Several other complications described, most probably unrelated to trial drugs }\end{array}$ \\
\hline \multicolumn{5}{|l|}{ Matched cohorts } \\
\hline McDougall $1994^{54}$ & $8 \mathrm{mg}$ & 10 years & $122 / 122$ & Fractures in $31 v 19$, cataracts in $36 v 22$, osteonecrosis in $5 v 2$ \\
\hline
\end{tabular}

*Three year results not analysed because of too many drop outs, ${ }^{14}$ treatment not randomised, ${ }^{22}$ or too low adherence to randomised treatment. ${ }^{23}$

†Average dose, all started with equivalent of $60 \mathrm{mg}$ prednisolone.

†Average dose, all started with $20 \mathrm{mg}$.

$95 \%$ confidence interval 0.3 to 4.6 ), while the standardised effect size of $0.90(-0.18$ to 2.00$)$, although not significant, was more comparable to the one we found.

\section{Adverse effects}

It is not easy to get a clear picture of the adverse effects of low dose steroids. Five of our short term studies did not report on side effects; one study reported that no side effects occurred ${ }^{38}$; two patients on prednisone had "subjective reactions" in one study ${ }^{34}$; and one patient developed acute psychosis while on prednisone in one study ${ }^{4041}$ The two remaining studies were moderate term studies from which we extracted short term efficacy data. ${ }^{62}{ }^{43}$ These studies did not report short term side effects but are included in the analysis of moderate or long term adverse effects below.

The meta-analysis of moderate term low dose steroid trials did not examine adverse effects at all..$^{52}$ The information in the most recently conducted two year placebo controlled trial is also sparse ${ }^{4}$; the aim of this study was to assess the progression of radiological damage, but films were taken only of the hands not of the lumbar spine, which could have detected any compression fractures. We reviewed moderate and long term randomised trials that had compared low dose steroids with placebo or a non-steroidal anti-inflammatory drug. We also identified cohort studies of rheumatoid arthritis that had compared patients treated with steroids with a matched, untreated control group. For this purpose we limited our broad search strategy to Explode "glucocorticoids, -synthetic" (adverse-effects) or Explode "glucocorticoids" (adverse-effects), combined with Explode "arthritis, -rheumatoid" (for all subheadings).

We found eight trials and two matched cohort studies (table 2). Spinal $x$ ray photographs were taken of all patients in three of the trials; four fractures were detected in a total of 83 patients randomised to prednisolone and one in 75 patients randomised to placebo. In the five remaining trials, comprising a total of 193 patients taking prednisolone and 190 taking placebo or aspirin, only one fracture with prednisolone and one with placebo were reported. No cases of cataract were reported in the trials. One of the trials was highly atypical as the starting dose was $300 \mathrm{mg}$ cortisone, equivalent to $60 \mathrm{mg}$ prednisolone. ${ }^{20-22}$ Its high number of adverse effects may therefore not be representative.

One of the cohort studies used a survival-type analysis and found a large difference in time to first adverse event, with a total of 92 events in the steroid group and 31 in the untreated group..$^{53}$ The risk of fracture increased with increasing doses: odds ratio 32.3 (95\% confidence interval 4.6 to 220$)$ for $>10-15 \mathrm{mg}$ prednisolone daily, 4.5 (2.1 to 9.6$)$ for $5-10 \mathrm{mg}$, and 1.9 (0.8 to 4.7 ) for less than $5 \mathrm{mg}$ daily. The overall risks for first event were 3.9 (0.8 to 18.1$)$ for fracture, 8.0 (1.0 to 64.0) for infection, and 3.3 (0.9 to 12.1) for gastrointestinal bleed or ulcer. This study also included patients who received oral steroid "pulses," which do not necessarily lead to the same incidence and severity of adverse effects as continuous low dose treatment. The other cohort study followed two groups of 122 patients for 10 years $^{54}$. Fractures were noted in 31 versus 19 patients, osteonecrosis in 5 versus 2 , and cataracts in 36 versus 22 (table 2).

The main problem with studies of matched cohorts is of course that the two groups can never be completely comparable as patients treated with steroids must be expected to be more severely affected than those not treated. This fact may escape notice by traditional measures of morbidity or the difference may be significant for one $\mathrm{e}^{54}$ or more ${ }^{53}$ indicators of severity of disease, as in the two cohort studies we reviewed. It is noteworthy, for example, that the first study found a similarly increased risk for fractures as for ulcers, ${ }^{53}$ though five meta-analyses of around 100 randomised trials of steroids in various diseases have shown either no increase in risk or, at most, a marginally increased risk of ulcers, which lacks clinical significance. ${ }^{55}$ Another meta-analysis of 71 randomised trials, which looked at the risk of infectious complications, showed no increase in risk in patients given less than $10 \mathrm{mg}$ prednisolone daily, and the relative risk for a mean dose under $20 \mathrm{mg}$ was only 1.3 (1.0 to 1.6 ), which contrasts with the eightfold increased risk in the cohort study. ${ }^{56}$ Although the confidence intervals were wide in 
- Prednisolone in low doses-that is, no more than $15 \mathrm{mg}$ daily -is highly effective in patients with rheumatoid arthritis

- The risk of adverse effects is acceptable in short, moderate, or long term use

- Oral low dose prednisolone may be used intermittently in patients with rheumatoid arthritis, particularly if the disease cannot be controlled by other means

- Further short term placebo controlled trials to study the clinical effect of prednisolone or other oral corticosteroids are no longer necessary

the cohort study, this illustrates the well known dangers of non-randomised comparisons.

Other treatments for rheumatoid arthritis-that is, non-steroidal anti-inflammatory drugs and slow acting antirheumatic drugs-have important adverse effects, which may occasionally even be life threatening. We therefore suggest that short term prednisolone in low doses-that is, not exceeding $15 \mathrm{mg}$ daily-may be used intermittently in patients with rheumatoid arthritis, particularly if they have flares in their disease that cannot be controlled by other means. This suggestion is in accordance with a recent detailed review of the adverse effects of low dose steroids. ${ }^{57}$ As prednisolone is highly effective, short term placebo controlled trials to study the clinical effect of low dose prednisolone or other oral corticosteroids are no longer necessary. If additional relevant trials are performed in future-for example, comparison of steroids with non-steroidal anti-inflammatory drugs-they will be included in the electronic version of this meta-analysis,$^{58}$ which will be continuously updated.

We are grateful for the unpublished data provided by Anke van Gestel and Roland Laan.

Contributors: PCG wrote the draft meta-analysis protocol and the draft manuscript. HKJ commented on the drafts. Both authors contributed to selection of studies and extraction of data. PCG is guarantor for the study.

Funding: Danish Medical Research Council.

Conflict of interest: None.

1 Hench PS, Kendall EC, Slocumb CH, Polley HF. The effect of a hormone of the adrenal cortex (17-hydroxy-11-dehydrocorticosterone: compound E) and of pituitary adrenocorticotropic hormone on rheumatoid arthritis. Proc Staff Meet Mayo Clin 1949:24:181-97.

2 Joint Committee of the Medical Research Council and Nuffield Foundation. A comparison of prednisolone with aspirin or other analgesics in the treatment of rheumatoid arthritis. Ann Rheum Dis 1959;18:173-88.

3 Weiss MM. Corticosteroids in rheumatoid arthritis. Sem Arthritis Rheum 1989;19:9-21.

4 Kirwan JR and the Arthritis and Rheumatism Council Low-dose Glucocorticoid Study Group. The effect of glucocorticoids on joint destruction in rheumatoid arthritis. N Engl J Med 1995;333:142-6.

5 Harris ED, Emkey RD, Nicols JE, Newberg A. Low dose prednisone therapy in rheumatoid arthritis: a double blind study. J Rheumatol 1983;10:713-21

6 Gestel AM van, Laan RFJM, Haagsma CJ, Putte LBA van de, Riel PLCM van. Oral steroids as bridge therapy in rheumatoid arthritis patients starting with parenteral gold. A randomized double-blind placebo-controlled trial. Br J Rheumatol 1995;34:347-51.

7 The Cochrane Library [database on disk and CD ROM]. Cochrane Collaboration. Oxford: Update Software; 1996-. Updated quarterly.

8 Mulrow CD, Oxman AD. Cochrane Collaboration Handbook, 3rd ed (updated 9 December 1996). Available in The Cochrane Library [database on disk and CD ROM]. Cochrane Collaboration; Issue 4. Oxford: Update Software; 1997. Updated quarterly.

9 DerSimonian R, Laird N. Meta-analysis in clinical trials. Controlled Clin Trials 1986;7:177-88

10 Badia Flores J. Valoracion del GP-40705 en la artritis reumatoide. Prensa Med Mex 1969; 34:382-4.
11 Chamberlain MA, Keenan J. The effect of low doses of prednisolone compared with placebo on function and on the hypothalamic pituitary adrenal axis in patients with rheumatoid arthritis. Rheumatol Rehabil 1976; $15: 17-23$.

12 Deodhar SD, Dick WC, Hodgkinson R, Buchanan WW. Measurement of clinical response to anti-inflammatory drug therapy in rheumatoid arthritis. QJ Med 1973;166:387-401.

13 Empire Rheumatism Council. Multi-centre controlled trial comparing cortisone acetate and acetyl salicylic acid in the long-term treatment of rheumatoid arthritis. Ann Rheum Dis 1955;14:353-63.

14 Empire Rheumatism Council. Multi-centre controlled trial comparing cortisone acetate and acetyl salicylic acid in the long-term treatment of rheumatoid arthritis. Ann Rheum Dis 1957;16:277-89.

15 Fearnley ME, Masheter HC. A controlled trial of flufenamic acid therapy in rheumatoid arthritis. Ann Phys Med 1966;8:204-7.

16 Fearnley ME. An investigation of possible synergism between flufenamic acid and prednisone. Ann Phys Med 1966;suppl:109-10.

17 Gum OB. A controlled study of two preparations, paramethasone, propoxyphene, and aspirin and propoxyphene and aspirin in the treatment of arthritis. Am J Med Sci 1966;251:328-32.

18 Jick H, Pinals RS, Ullian R, Slone D, Muench H. Dexamethasone and dexamethasone-aspirin in the treatment of chronic rheumatoid arthritis. Lancet 1965;ii:1203-5.

19 Jick H, Slone D, Dinan B, Muench H. Evaluation of drug efficacy by a preference technic. N Engl J Med 1966;275:1399-403.

20 Joint Committee of the Medical Research Council and Nuffield Foundation. A comparison of cortisone and aspirin in the treatment of early cases of rheumatoid arthritis. BMJ 1954;i:1223-7.

21 Joint Committee of the Medical Research Council and Nuffield Foundation. A comparison of cortisone and aspirin in the treatment of early cases of rheumatoid arthritis. BMJ 1955;ii:695-700.

22 Joint Committee of the Medical Research Council and Nuffield Foundation. Long-term results in early cases of rheumatoid arthritis treated with either cortisone or aspirin. BMJ 1957;i:847-50.

23 Joint Committee of the Medical Research Council and Nuffield Foundation. Comparison of prednisolone with aspirin or other analgesics in the treatment of rheumatoid arthritis. Ann Rheum Dis 1960;19:331-7.

24 Kvien TK, Hoyeraal HM, Sandstad B. Assessment methods of disease activity in juvenile rheumatoid arthritis-evaluated in a prednisolone/ placebo double-blind study.J Rheumatol 1982; 9:696-702.

25 Million R, Kellgren JH, Poole P, Jayson MIV. Long-term study of management of rheumatoid arthritis. Lancet 1984;i:812-6.

26 Murthy MHV, Rhymer AR, Wright V. Indomethacin or prednisolone at night in rheumatoid arthritis? Rheumatol Rehab 1978;17:8-13.

27 Siegmeth W, Herkner W. Erfahrungen mit einem neuen Kombinationspräparat (Realin) bei der Behandlung akuter rheumatischer Zustandsbilder. Wien Med Wochenschr 1974;124:569-73.

28 Slonim RR, Kiem IM, Howell DS, Brown HE. Evaluation of drug responses in the patient severely afflicted with rheumatoid arthritis. $J$ Florida Med Assoc 1969;56:336-41.

29 Webb J, Downie WW, Dick WC, Lee P. Evaluation of digital joint circumference measurements in rheumatoid arthritis. Scand I Rheumatol 1973;2:127-31.

30 West HF. Rheumatoid arthritis. The relevance of clinical knowledge to research activities. Abstracts World Med 1967;41:401-17.

31 Zuckner J, Uddin J, Ramsey RH. Adrenal-pituitary relationships with prolonged low dosage steroid therapy in rheumatoid arthritis. Missouri Med 1969;66:649-58.

32 Laan RFJM, Riel PLCM van, Putte LBA van de, Erning LJTO van, Hof MA van't, Lemmens JAM. Low-dose prednisone induces rapid reversible axial bone loss in patients with rheumatoid arthritis. Ann Intern Med 1993;119:963-8.

33 Berry H, Huskisson EC. Isotopic indices as a measure of inflammation in rheumatoid arthritis. Ann Rheum Dis 1974;33:523-5.

34 Boardman PL, Dudley Hart F. Clinical measurement of the antiinflammatory effects of salicylates in rheumatoid arthritis. BMJ 1967;iv:264-8.

35 Böhm C. Zur medikamentosen Langzeittherapie der primarchronischen Polyarthritis. Med Welt 1967;35:2047-50.

36 Schoger GA. Zur beurteilung der Wirkung einer Kombination von Salicylaten und Prednisolon bei rheumatischen Erkrankungen. ArzneimittelForschung 1968; 18:758-60.

37 Dick WC, Nuki G, Whaley K, Deodhar S, Buchanan WW. Some aspects in the quantitation of inflammation in joints of patients suffering from rheumatoid arthritis. Rheumatol Phys Med 1970;suppl 10:40-7.

38 Jasani MK, Downie WW, Samuels BM, Buchanan WW. Ibuprofen in rheumatoid arthritis. Ann Rheum Dis 1968;27:457-62.

39 Lee P, Jasani MK, Dick WC, Buchanan WW. Evaluation of a functional index in rheumatoid arthritis. Scand J Rheumatol 1973;2:71-7.

40 Lee P, Webb J, Anderson J, Buchanan WW. Method for assessing therapeutic potential of anti-inflammatory antirheumatic drugs in rheumatoid arthritis. BMJ 1973;ii:685-8.

41 Lee P, Anderson JA, Miller J, Webb J, Buchanan WW. Evaluation of analgesic action and efficacy of antirheumatic drugs. J Rheumatol 1976;3:28394.

42 Lee P, Baxter A, Carson Dick W, Webb J. An assessment of grip strength measurement in rheumatoid arthritis. Scand J Rheumatol 1974;3:17-23.

43 Stenberg VI, Fiechtner JJ, Rice JR, Miller DR, Johnson LK. Endocrine control of inflammation: rheumatoid arthritis. Double-blind, crossover clinical trial. Int J Clin Pharm Res 1992;12:11-8.

44 Gøtzsche PC. Meta-analysis of grip strength: most common, but superfluous variable in comparative NSAID trials. Dan Med Bull 1989;36:493-5.

45 Gøtzsche PC. Sensitivity of effect variables in rheumatoid arthritis: a meta-analysis of 130 placebo controlled NSAID trials. J Clin Epidemiol 1990;43:1313-8 
46 Schulz KF, Chalmers I, Hayes RJ, Altman D. Empirical evidence of bias: dimensions of methodological quality associated with estimates of treatment effects in controlled trials. JAMA 1995:273:408-12.

47 Gøtzsche PC. Methodology and overt and hidden bias in reports of 196 double-blind trials of nonsteroidal, antiinflammatory drugs in rheumatoid arthritis. Controlled Clin Trials 1989;10:31-56 (erratum:356).

48 Dickersin K, Min Y-I. NIH clinical trials and publication bias. Online J Curr Clin Trials 1993 Apr 28;Doc No 50.

49 Stern JM, Simes RJ. Publication bias: evidence of delayed publication in a cohort study of clinical research projects. BMJ 1997;315:640-5.

50 Gøtzsche PC. Bias in double-blind trials (thesis). Dan Med Bull 1990;37:329-36.

51 Savulescu J, Chalmers I, Blunt J. Are research ethics committees behaving unethically? Some suggestions for improving performance and accountability. BMJ 1996;313:1390-3.

52 Saag KG, Criswell LA, Sems KM, Nettleman MD, Kolluri S. Low-dose corticosteroids in rheumatoid arthritis. A meta-analysis of their moderate-term effectiveness. Arthritis Rheum 1996;39:1818-25.

53 Saag KG, Koehnke R, Caldwell JR, Brasington R, Burmeister LF, Zimmerman $\mathrm{B}$, et al. Low dose long-term corticosteroid therapy in rheu- matoid arthritis: an analysis of serious adverse events. Am J Med 1994;96:115-23

54 McDougall R, Sibley J, Haga M, Russell A. Outcome in patients with rheumatoid arthritis receiving prednisone compared to matched controls.J Rheumatol 1994;21:1207-13.

55 Gøtzsche PC. Steroids and peptic ulcer: an end to the controversy [editorial]? J Intern Med 1994;236:599-601.

56 Stuck AE, Minder CE, Frey FJ. Risk of infectious complications in patients taking glucocorticosteroids. Rev Infect Dis 1989;11:954-63.

57 Caldwell JR, Furst DE. The efficacy and safety of low-dose corticosteroids for rheumatoid arthritis. Sem Arthritis Rheum 1991;21:1-11.

58 Gøtzsche PC, Johansen HK. Short-term low-dose corticosteroids vs placebo and nonsteroidal antiinflammatory drugs in rheumatoid arthritis. In: Tugwell P, Brooks P, Wells G, de Bie R, Bosi-Ferraz M, Gillespie W, eds. Musculoskeletal module. Cochrane Database of Systematic Reviews. The Cochrane Library. Cochrane Collaboration; Issue 4. Oxford: Update Software; 1997. Updated quarterly.

(Accepted 18 November 1997)

\title{
Effects of the Heartbeat Wales programme over five years on behavioural risks for cardiovascular disease: quasi-experimental comparison of results from Wales and a matched reference area
}

\author{
Chris Tudor-Smith, Don Nutbeam, Laurence Moore, John Catford
}

Health Promotion Wales, Ffynnon-las, Llanishen, Cardiff CF4 5DZ

Chris Tudor-Smith, director of research and development

Department of Public Health and

Community

Medicine,

University of

Sydney, NSW 2006,

Australia

Don Nutbeam,

professor of public

health

University of

Bristol, Department

of Social Medicine,

Canynge Hall,

Bristol BS8 2PR

Laurence Moore,

lecturer in health

services research

Deakin University, Burwood, Victoria

3125, Australia

John Catford,

professor of health

strategies

Correspondence to: Mr Tudor-Smith chris.tudorsmith@ hpw.wales.nhs.uk

BMJ 1998;316:818-22

\begin{abstract}
Objective: To assess the net 5 year effects of intervention of a community based demonstration project, the Heartbeat Wales programme, on modifiable behavioural risks for prevention of cardiovascular disease.

Design and setting: Quasi-experimental design comparing results from two independent cross sectional population surveys conducted in 1985 and 1990 in Wales and a matched reference area in north east England.
\end{abstract}

Subjects: Random, stratified samples of people aged 18-64 years (18 538 in 1985 and 13045 in 1990) in Wales and in north east England (1483 and 4534, respectively).

Intervention: A coordinated range of activities for heart health promotion in Wales entailing public education campaigns along with supportive policy and infrastructure change. In the reference area no additional community heart health promotion was planned, though considerable activity did take place, "contaminating" the reference area.

Main outcome measures: Fifteen self reported behavioural indicators relating to dietary choice, smoking, frequency of exercise, and weight.

Results: Positive changes (for health) in behavioural outcomes were observed among the population in Wales, including a reduction in reported smoking prevalence and improvements in dietary choice. There was no net intervention effect for the programme over and above observed change in the reference area.

Conclusions: No definite conclusions can be drawn concerning the efficacy of the programme in terms of behavioural outcomes. With hindsight, the difficulties of evaluating such a complex multifaceted intervention were underestimated. Further debate on the most appropriate methods for assessing the effectiveness of community based health promotion programmes is called for.

\section{Introduction}

Cardiovascular disease remains one of the major causes of morbidity and premature mortality in the United Kingdom. ${ }^{1}$ During the 1980 s a consensus evolved on the need to reduce this toll of ill health and death through population-wide preventive measures (see, for example, papers by the World Health Organisation $^{2}$ and Rose et $\mathrm{al}^{3}$ ). The Welsh Office and the existing national agency for health education, the Health Education Council, agreed to establish a community based demonstration programme in Wales directed towards reducing modifiable behavioural risks for cardiovascular disease.

The programme was publicly launched in 1985 as Heartbeat Wales with three strategic aims: leadership - to coordinate, support, initiate, and monitor action at local and regional levels which would encourage improvements in modifiable behavioural risks for prevention of cardiovascular disease; demonstration-to stimulate, disseminate, and assist the development of strategies and programmes to promote health and prevent cardiovascular disease throughout the United Kingdom; and experimentation - to research, develop, and evaluate a range of new projects and initiatives for heart health promotion and provide feedback on their feasibility and impact. ${ }^{4}$

Heartbeat Wales drew on the experiences of other community based risk reduction programmes for cardiovascular disease, particularly those in Finland and the United States. ${ }^{5-8}$ The programme used a range 